\title{
SOM230: a novel somatostatin peptidomimetic with broad somatotropin release inhibiting factor (SRIF) receptor binding and a unique antisecretory profile
}

\author{
C Bruns, I Lewis, U Briner, G Meno-Tetang and G Weckbecker \\ Novartis Pharma AG, Research Transplantation, WSJ-386, CH - 4002 Basel, Switzerland \\ (Correspondence should be addressed to C Bruns; Email: Christian.Bruns@pharma.novartis.com,or G Weckbecker; \\ Email: Gisbert.Weckbecker@pharma.novartis.com)
}

(C Bruns and G Weckbecker contributed equally to this work)

\begin{abstract}
Objective: The aim of the present study was to identify a small, metabolically stable somatotropin release inhibiting factor (SRIF) analog with a more universal binding profile similar to that of natural somatostatin, resulting in improved pharmacological properties and hence new therapeutic uses. Design: A rational drug design approach was followed by synthesizing alanine-substituted SRIF-14 analogs to determine the importance of single amino acids in SRIF-14 for SRIF receptor subtype binding. The incorporation of structural elements of SRIF-14 in a stable cyclohexapeptide template in the form of modified unnatural amino acids resulted in the identification of the novel cyclohexapeptide SOM230.

Results: SOM230 binds with high affinity to SRIF receptor subtypes sst1, sst2, sst3 and sst5 and displays a 30- to 40-fold higher affinity for sst1 and sst5 than Sandostatin (octreotide; SMS 201-995) or Somatuline (BIM 23014). In vitro, SOM230 effectively inhibited the growth hormone releasing hormone $(\mathrm{GHRH})$-induced growth hormone $(\mathrm{GH})$ release in primary cultures of rat pituitary cells with an $\mathrm{IC}_{50}$ of $0.4 \pm 0.1 \mathrm{nmol} / \mathrm{l}(n=5)$. In vivo, SOM230 also potently suppressed $\mathrm{GH}$ secretion in rats. The $\mathrm{ED}_{50}$ values determined at $1 \mathrm{~h}$ and $6 \mathrm{~h}$ post injection of SOM230 indicated its very long duration of action in vivo. This property was also reflected in pharmacokinetic studies comparing plasma levels of SMS 201-995 and SOM230 after subcutaneous application. Whereas SMS 201-995 had a terminal elimination half life of $2 \mathrm{~h}$, this was markedly prolonged in SOM230-treated animals $\left(\mathrm{t}_{1 / 2}=23 \mathrm{~h}\right)$. Furthermore, in rats SOM230 demonstrated a much higher efficacy in lowering plasma insulinlike growth factor-I (IGF-I) levels compared with SMS 201-995. The infusion of $10 \mu \mathrm{g} / \mathrm{kg} / \mathrm{h}$ of SOM230 using subcutaneously implanted minipumps decreased plasma IGF-I levels far more effectively than SMS 201-995. After 126 days of continuous infusion of SOM230 plasma IGF-I levels were decreased by $75 \%$ of placebo-treated control animals. For comparison SMS 201-995, when used under the same experimental conditions, resulted in only a $28 \%$ reduction of plasma IGF-I levels, indicating a much higher efficacy for SOM230 in this animal model. It is important to note that the inhibitory effect of SOM230 was relatively selective for GH and IGF-I in that insulin and glucagon secretion was inhibited only at higher doses of SOM230. This lack of potent inhibition of insulin and glucagon release was also reflected in the lack of effect on plasma glucose levels. Even after high dose treatment over 126 days no obvious adverse side effects were noticed, including changes in plasma glucose levels.

Conclusion: We have identified a novel short synthetic SRIF peptidomimetic, which exhibits high affinity binding to four of the five human SRIF receptor subtypes and has potent, long lasting inhibitory effects on GH and IGF-I release. Therefore SOM230 is a promising development candidate for effective GH and IGF-I inhibition and is currently under evaluation in phase 1 clinical trials.
\end{abstract}

European Journal of Endocrinology 146 707-716

\section{Introduction}

The peptide hormone somatostatin (somatotropin release inhibiting factor; SRIF), discovered by Brazeau et al. (1), is a cyclopeptide consisting of 14 or 28 amino acids which is expressed in many tissues throughout the body including the central nervous system, hypothalamus, gastrointestinal (GI) tract, and the pancreas $(1,2)$. Somatostatin peptides bind with high affinity to somatostatin receptors expressed on target tissues, thereby exerting a large number of biological effects. Somatostatins are important regulators 
of endocrine and exocrine secretion and affect the release of many hormones such as growth hormone $(\mathrm{GH})$, glucagon, insulin, gastrin, secretin and thyroidstimulating hormone (TSH) (2). The neuro-endocrine activity of SRIF is reflected by its effective inhibition of $\mathrm{GH}$ release from the pituitary gland thereby indirectly also affecting insulin-like growth factor-I (IGF-I) release in the liver and other peripheral organs such as heart and kidney (3). In the central nervous system SRIF peptides act as neuromodulators and neurotransmitters (4).

These biological effects of SRIF are mediated by G-protein-coupled SRIF receptors, of which five human SRIF receptor subtypes, hsst1-5, have been cloned over the past years $(5-8)$. The sequence homology between receptor subtypes varies between 39 and 57\% with great sequence homology seen in the transmembrane domains $(9-11)$. All five SRIF receptor subtypes modulate various intracellular signaling pathways such as adenylyl cyclase, ion channels $\left(\mathrm{K}^{+}, \mathrm{Ca}^{2+}\right)$, serine/threonine- and tyrosine-phosphatases as well as phospholipase A2 $(10,12)$.

Natural somatostatins (SRIF-14, SRIF-28) bind with high affinity to all 5 human SRIF receptor subtypes, hsst1-5 $(5,10,13)$. However, the therapeutic use of SRIF peptides is limited by the rapid proteolytic degradation in plasma $\left(\mathrm{t}_{1 / 2} \leq 3 \mathrm{~min}\right)$ requiring continuous infusion regimens. A number of short synthetic SRIF analogs with improved metabolic stability have been synthesized in the past but Sandostatin (octreotide, SMS 201-995 (14)) and Somatuline (lanreotide, BIM 23014 (15)) are the only two synthetic SRIF analogs approved for clinical use. These analogs are used in the clinic to treat disorders characterized by the excessive production of certain hormones such as GH, gastrin, secretin, glucagon and insulin (16-18). In contrast to SRIF-14 and SRIF-28, Sandostatin or Somatuline bind with high sub-nanomolar affinity to hsst 2 only, have reduced affinity for hsst 3 and hsst5, and show very low or absent binding affinity for hsst1 and hsst4 $(5,10,12)$.

Although the expression profile of SRIF receptor subtypes has been studied in a large number of tissues of various species, only a few functional responses can specifically be assigned to a single SRIF receptor subtype. One example is the effective inhibition of growth hormone release by SRIF analogs that bind to the sst2 and sst5 subtype (19-21). This incomplete understanding is largely due to the lack of subtype-selective ligands, especially SRIF receptor antagonists.

Assuming that the unique pharmacological effects documented for SRIF-14 are due to its universal high affinity binding to all five somatostatin receptor subtypes, sst1-5, we aimed at identifying short, metabolically stable rather universal SRIF peptidomimetics with improved properties and therefore potential new therapeutic applications in diseases where Sandostatin and Somatuline were shown to be weakly active or even ineffective. The transposition of important functional groups from SRIF-14 into a reduced size, stable cyclohexapeptide template resulted in the discovery of SRIF peptidomimetics with an almost universal binding profile. Here we present for the first time the in vitro and in vivo characterization of the new metabolically stable cyclohexapeptide SOM230 with broad SRIF receptor binding and a unique inhibitory profile in vivo in rats. SOM230 is a promising development candidate that is currently under investigation in early phase I clinical trials.

\section{Materials and methods}

\section{SRIF receptor subtype binding}

Binding experiments were performed with membranes prepared from CHO (hsst1-4) and COS (hsst5) cells expressing the respective human SRIF receptor subtype as reported previously $(5,22)$. Briefly, $\left.{ }^{125} \mathrm{I}\right] \mathrm{Tyr}^{11}$ SRIF-14 was used as an SRIF receptor-specific radioligand. Ten micrograms membrane protein were incubated in $10 \mathrm{mmol} / \mathrm{l}$ Hepes $(\mathrm{pH} 7.5)$, containing $5 \mathrm{mmol} / \mathrm{l} \mathrm{MgCl}_{2}, 15 \mu \mathrm{mol} / \mathrm{l}$ bacitracin, $0.5 \%(\mathrm{w} / \mathrm{v})$ bovine serum albumin, and 30000 c.p.m. $(20 \mathrm{pmol} / \mathrm{l})$ ${ }^{125}$ I-labeled $\left[\mathrm{Tyr}^{11}\right]$-SRIF-14 $(2000 \mathrm{Ci} / \mathrm{mmol})$. Radioligand binding was determined by incubating membranes for $1 \mathrm{~h}$ at room temperature in the presence or absence of various concentrations of unlabeled somatostatin-14, or the respective SRIF analog. The incubation was stopped by rapid filtration through Whatman GF/C glass fiber filters, and subsequent washing with $10 \mathrm{mmol} / \mathrm{l}$ Tris $/ 150 \mathrm{mmol} / \mathrm{l} \mathrm{NaCl}$ buffer (pH 7.5) by the use of a 48-well harvesting device (Brandel, Gaithersburg, MD, USA). Specific binding was measured as total $\operatorname{Tyr}^{11}\left[{ }^{125} \mathrm{I}\right]-$ SRIF-14 binding minus the amount of radioligand bound in the presence of $100 \mathrm{nmol} / \mathrm{l} \mathrm{SRIF-14}$ (non-specific binding).

\section{GH release in vitro}

The inhibitory effect of SOM230 on growth hormone secretion in vitro was evaluated using primary cultures of rat anterior pituitary cells. Pituitary glands were removed from 10-15 Wistar rats with a mean body weight of $200 \mathrm{~g}$ (Biological Research Laboratory, Füllinsdorf, Switzerland). The pituitary cells were prepared as described previously (23). Pituitary cells were cultured for 4 days in minimum essential medium, supplemented with 5\% fetal calf serum, 5\% horse serum, $43 \mathrm{mmol} / \mathrm{l} \mathrm{NaHCO}_{3}, 100 \mathrm{ng} / \mathrm{l}$ streptomycin, and $10^{-5} \mathrm{U} / \mathrm{l}$ penicillin. The SRIF analogs were administered in the presence of (D) $\mathrm{Ala}^{2}-\mathrm{GH}$ releasing hormone (1-29) (GHRH) amide (3× $10^{-10} \mathrm{~mol} / \mathrm{l}$ ), and incubated for $3 \mathrm{~h}$. The concentration of $\mathrm{GH}$ in the supernatant was determined by means of a radioimmunoassay (RIA) procedure. 


\section{Inhibition of hormone release in rats}

Male rats (Ico:OFA-SD, 200-300 g, Iffa-Credo, Lyon, France) were anesthetized with pentobarbital-sodium, $60 \mathrm{mg} / \mathrm{kg}$ i.p., and the compounds were given subcutaneously. Blood was collected after decapitation (GH, IGF-I), or from the portal vein (insulin, glucagon) after the indicated times post application of the respective SRIF analog. To determine the duration of action, the inhibitory effect on the $\mathrm{GH}$ secretion $6 \mathrm{~h}$ post drug application was determined. Unanesthetized rats were pretreated with the respective compound. Five hours later they received the pentobarbital anesthesia and blood was collected one hour later, six hours after the start of drug treatment. Glucagon secretion was stimulated with insulin (porcine, U40, Hoechst, Germany, $1 \mathrm{U} / \mathrm{kg}$ i.v. for $15 \mathrm{~min}$ ).

In each experiment 5-6 animals were used per dose, including control groups receiving only vehicle. The $\mathrm{ID}_{50}$ value for the inhibition of hormone secretion was determined graphically (log-probit) for each experiment. Each compound was tested in at least 2 independent experiments. All animals were housed under standardized housing conditions (food, light, temperature). The RIA for rat (r) GH used NIAMD-rGH-RP1 as standard, monkey anti-rGH as antiserum (produced in-house) and goat anti-monkey IgG as second antibody. $\left[{ }^{125} \mathrm{I}\right] \mathrm{rGH}$ was labeled and purified in-house shortly before analysis.

\section{IGF-I release in rats}

Male Lewis rats (LEW/Ola/Hsd, Harlan, Netherlands) weighing 200-250g were used in this study. SMS 201-995 and SOM230 were dissolved in sterile water and put in Alzet osmotic minipumps (model 2002, Charles River SA, Saint-Aubin, France), delivering $0.5 \mu \mathrm{l} / \mathrm{h}$. The concentrations were adjusted to the mean body weight of rats, under consideration of a certain weight gain during the experiment, in order to obtain an average dose of $10 \mu \mathrm{g} / \mathrm{kg} / \mathrm{h}$. For control animals, osmotic pumps were filled with sterile water only. Long-term infusions were maintained for up to 126 days by replacing the minipumps every 2 weeks. The pumps were implanted s.c. on the back using a short anesthesia with isofluran (Forene, Abbott AG, Cham, Switzerland). Blood samples were collected before implantation of the osmotic pumps and on various days afterwards. The animals were anesthetized with isofluran, and blood was collected alternately from the left and right retroorbital plexus. After 126 days animals were killed. Blood was collected in Eppendorf tubes containing EDTA (WED-19, Milian SA, Geneva, Switzerland). The plasma was separated and frozen until analysis of IGF-I levels. IGF-I was determined by RIA using the IGF-I kit from Nichols Institute Diagnostics SA (Geneva, Switzerland) containing rabbit anti-IGF-I antiserum, goat anti-rabbit as second antibody, $\left[{ }^{125}\right.$ I]IGF-I and a standard.

\section{Pharmacokinetic data analysis in rat}

A two-compartment open model with first order absorption and first order elimination was used to analyze mean data $(n=4)$. Plasma concentration versus time data for SOM230 and SMS 201-995 after subcutaneous administration were described by the following equation:

$$
C=A \cdot e^{-\alpha \cdot t}-B \cdot e^{-\beta \cdot t}-(A+B) \cdot e^{-k a \cdot t}
$$

The intercept coefficients (A and B), slopes ( $\alpha$ and $\beta$ ), and absorption rate constant (ka) were estimated by least-squares regression analysis using the ADAPT II.4 program (24). The distribution half-life was derived from the slope $\alpha\left(t_{1 / 2 \alpha}=0.693 / \alpha\right)$ and the terminal elimination half-life was derived from the slope $\beta$ $\left(t_{1 / 2 \beta}=0.693 / \beta\right)$.

\section{Results}

\section{SOM230 molecule}

Figure 1 shows for comparison the structures of SRIF14, SMS 201-995, and SOM230. Assuming that the unique pharmacological effects of SRIF-14 are mediated by its universal high affinity binding to sst1-5, and knowing that SRIF-14 has a very short duration of action in vivo (plasma half life $\leq 3 \mathrm{~min}$ ), the goal of this project was to identify and characterize a short synthetic SRIF analog with novel binding and improved functional properties and a long duration of action in vivo. Important structure-activity information was obtained by synthesizing Ala-substituted SRIF-14 analogs ('Ala-Scan') and investigating their binding to the five human SRIF receptor subtypes (Fig. 2). The Ala substitution of amino acids in SRIF14 allowed us to determine the importance of the respective position in SRIF-14 for universal high affinity binding to hsst1-5. This rational approach revealed that the $\beta$-turn region with $\operatorname{Trp}^{8}$ and Lys ${ }^{9}$ as well as adjacent regions with $\mathrm{Lys}^{4}, \mathrm{Phe}^{6}, \mathrm{Phe}^{7}$ and Phe ${ }^{11}$ contain essential residues for the universal binding profile of SRIF-14 to hsst1-5. To identify small, stable SRIF analogs with a more universal binding profile similar to SRIF, a derivatization program was initiated with the aim to transpose structural elements of SRIF-14 in a reduced size stable cyclohexapeptide template. The incorporation of $\mathrm{Lys}^{4}$ in the form of a novel basic trans-(L)hydroxyproline aminoethylurethane extension, phenylglycine (Phg), O-benzyltyrosine (Tyr(Bzl)), and D-Trp to corresponding positions resulted in SOM 230 (Fig. 1c). 
a)

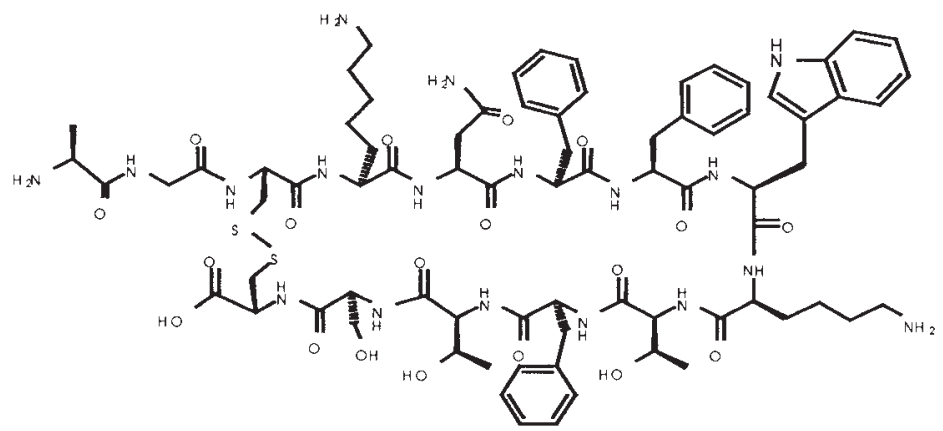

\section{SRIF-14}

b)

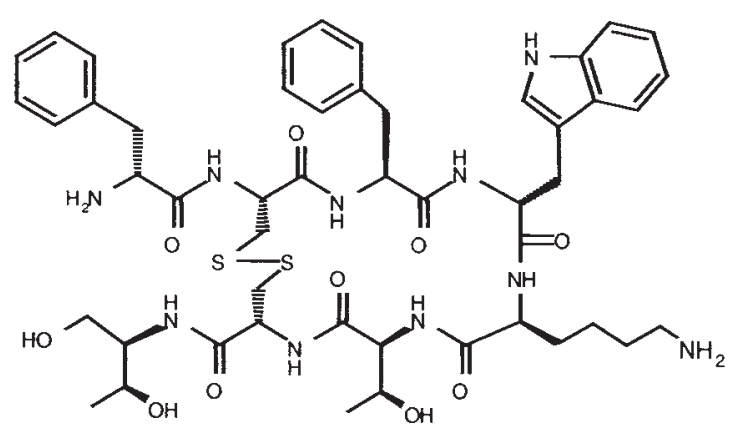

SMS 201-995

c)

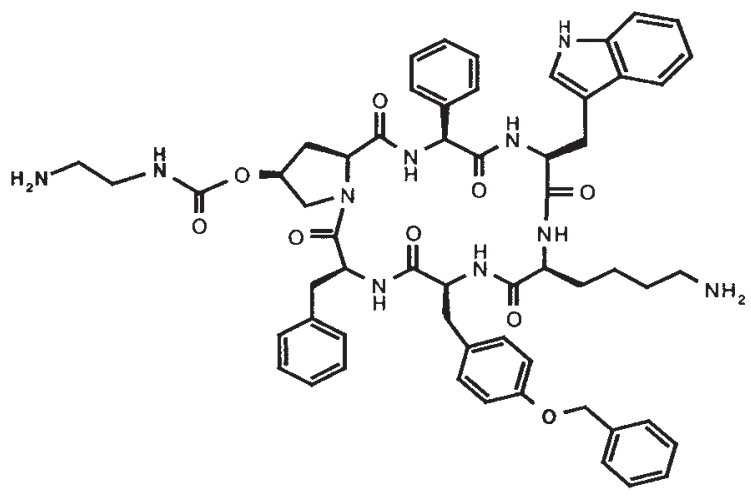

\section{SOM230}

Figure 1 Structural comparison of (a) SRIF-14, (b) SMS 201-995 and (c) SOM230.

www.eje.org 


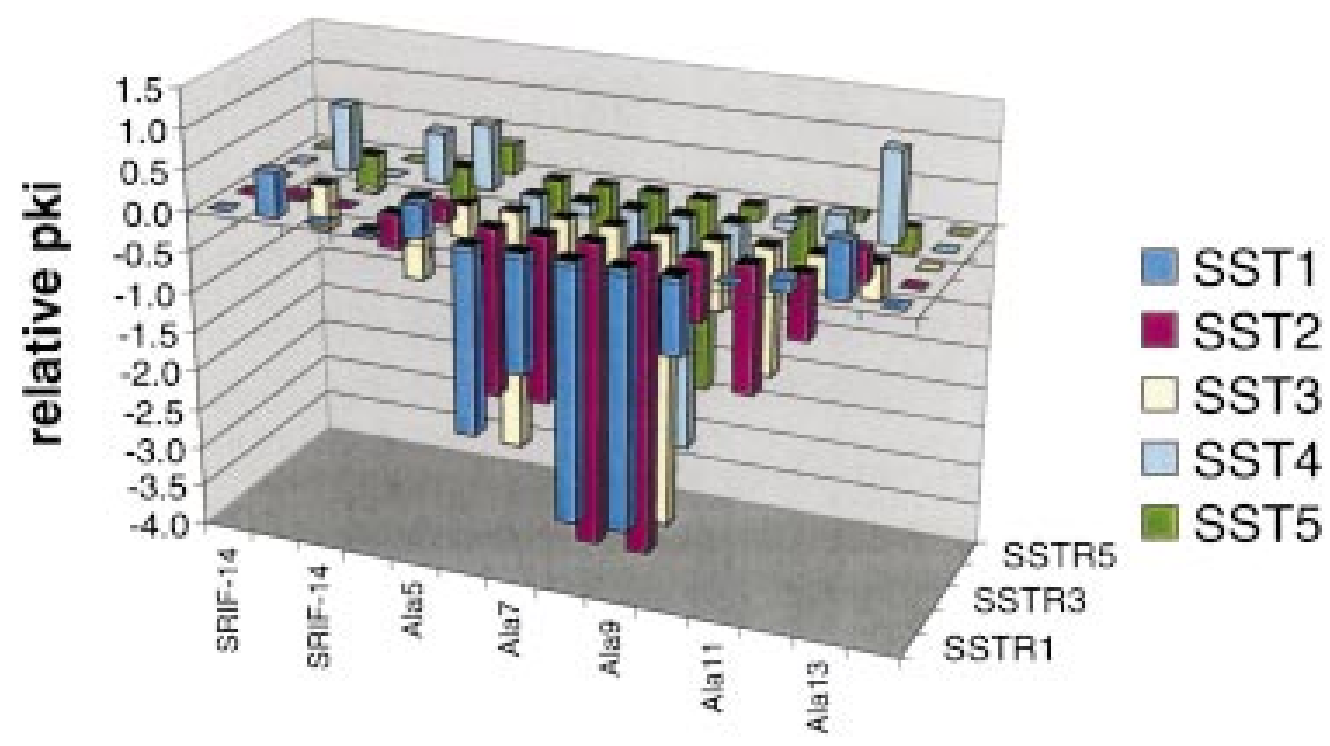

Figure 2 'Ala-Scan' of SRIF-14, comparing binding affinities of Ala-substituted SRIF-14 analogs for each human somatostatin receptor subtype, hsst1-5 (SSTR1-5, SST1-5).

\section{Binding affinities of SOM230 for human somatostatin receptor subtypes}

The synthetic approaches for obtaining short SRIF analogs with a universal binding profile were guided by competition binding experiments using $\mathrm{CHO}$ (COS) cell membranes expressing the respective human SRIF receptor subtype (hsst1-5) and $\mathrm{Tyr}^{11}\left[\mathrm{I}^{125}\right]$ SRIF-14 as SRIF receptor specific ligand. SRIF-14 binds with high affinity to all five human SRIF receptor subtypes (Table 1) with the binding affinity for hsst2 (0.15 \pm $0.02 \mathrm{nmol} / \mathrm{l} ; n=7)$ and hsst5 (0.29 $\pm 0.04 \mathrm{nmol} / \mathrm{l} ; n=$ 7) being the highest. In contrast, the two short synthetic SRIF analogs used in the clinic, Sandostatin (octreotide, SMS 201-995) and Somatuline (lanreotide, BIM 23014) primarily bind with high affinity to the hsst2 subtype but show reduced or no binding to the hsst 1, 3, 4 and 5 subtypes. The novel cyclohexapeptide analog, SOM230, exhibits a very different binding profile to human somatostatin receptors hsst $1-5$. When structural elements from SRIF-14 were transposed into the cyclohexapeptide template, an SRIF-like affinity profile with high affinity binding to all human SRIF receptor subtypes except hsst4 was obtained (Table 1). When compared with Sandostatin and Somatuline, SOM230 exhibits a 20 to 30 times higher binding affinity to hsst1, and a 40 to 100 times higher binding affinity to hsst5, respectively. Interestingly, SOM230 demonstrates one of the highest binding affinities to hsst5 ever reported for an SRIF analog, which is even two times higher than that measured for SRIF-14. Moreover, the affinity of SOM230 for hsst3 is five times higher compared with SMS 201-995 (Table 1).

In order to determine the specificity of SOM230 binding for SRIF receptor subtypes, a broad range receptor screen was performed. The receptor families tested included adenosine, adreno, benzodiazepine, dopamine, GABA, histamine, serotonine, opioid and muscarinic receptors as well as $\mathrm{K}^{+}$and $\mathrm{Ca}^{2+}$ channels. SOM230 did not show a significant affinity for any of the receptors assessed with the exception of a very weak affinity for the opiate $\kappa$ binding site $\left(\mathrm{pk}_{\mathrm{i}}=6.09\right.$, data not shown $)$.

An important question was whether this unique binding profile of SOM230 for SRIF receptor subtypes would translate into an improved inhibitory profile when compared with Sandostatin.

Table 1 Binding affinities of SRIF-14, Somatuline (BIM 23014), Sandostatin (SMS 201-995) and SOM230 for the five human SRIF receptor subtypes, hsst1-5. Results are the mean \pm S.E.M IC $\mathrm{I}_{50}$ values expressed as $\mathrm{nmol} / \mathrm{l}$.

\begin{tabular}{|c|c|c|c|c|c|}
\hline Compound & hsst1 & hsst2 & hsst3 & hsst4 & hsst5 \\
\hline SRIF-14 & $0.93 \pm 0.12(n=6)$ & $0.15 \pm 0.02(n=7)$ & $0.56 \pm 0.17(n=7)$ & $1.5 \pm 0.4(n=7)$ & $0.29 \pm 0.04(n=7)$ \\
\hline Somatuline (BIM 23014) & $180 \pm 20 \quad(n=3)$ & $0.54 \pm 0.08(n=3)$ & $(n=3)$ & $230 \pm 40 \quad(n=3)$ & $17 \pm 5 \quad(n=3)$ \\
\hline Sandostatin (SMS 201-995) & $280 \pm 80 \quad(n=4)$ & $0.38 \pm 0.08(n=5)$ & $7.1 \pm 1.4 \quad(n=4)$ & $>1000(n=4)$ & $6.3 \pm 1.0 \quad(n=3)$ \\
\hline SOM230 & $9.3 \pm 0.1 \quad(n=4)$ & $1.0 \pm 0.1 \quad(n=4)$ & $1.5 \pm 0.3 \quad(n=4)$ & $>100 \quad(n=4)$ & $0.16 \pm 0.01(n=4)$ \\
\hline
\end{tabular}




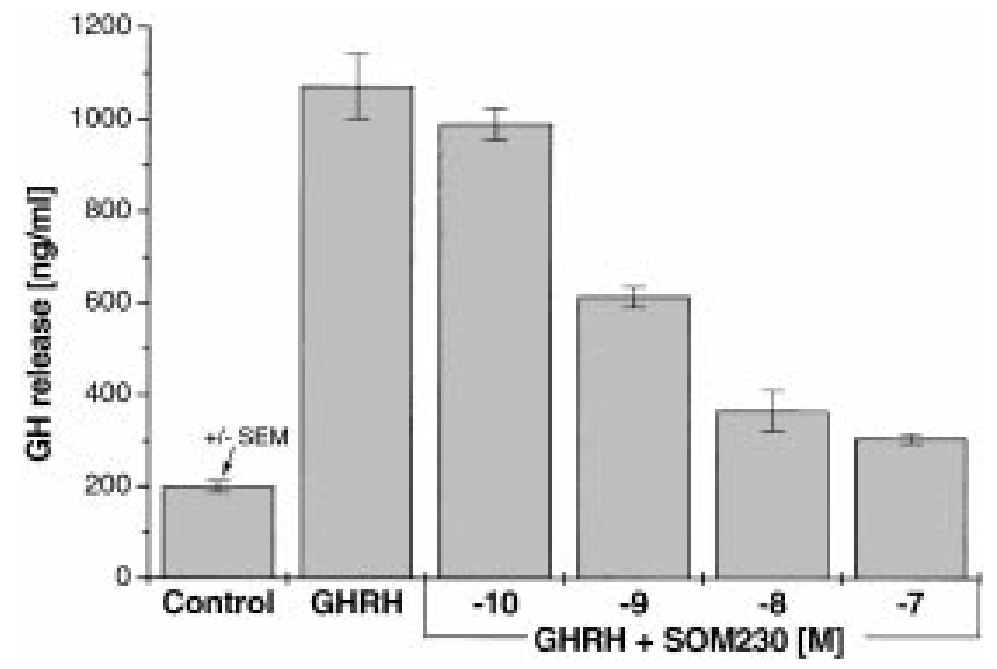

Figure 3 Dose-dependent inhibition of the $\mathrm{GHRH}$-stimulated $\mathrm{GH}$ release in vitro by SOM230 using primary cultures of rat anterior pituitary cells. The control represents basal $\mathrm{GH}$ release without $\mathrm{GHRH}$-stimulation. Data represent means \pm S.E.M. of a representative experiment with triplicate determinations for each SOM230 concentration.

\section{Inhibition of GH release in vitro by SOM230}

The inhibitory effect of SOM230 on GHRH-induced GH release was measured in vitro using primary cultures of rat pituitary cells. SRIF-14 and SMS 201-995 inhibited the $\mathrm{GH}$ release in vitro at nanomolar concentrations. In accordance with its high binding affinity for sst 2 and especially sst5, SOM230 most effectively inhibited in a dose-dependent manner the GHRH-induced GH release in vitro with an $\mathrm{IC}_{50}$ of $0.4 \pm 0.1 \mathrm{nmol} / \mathrm{l}(n=5)$ indicating its high potency for $\mathrm{GH}$ inhibition (Fig. 3). The $\mathrm{IC}_{50}$ values for SRIF-14 and SMS 201-995 measured under the same experimental conditions were $1.5 \pm 0.3 \mathrm{nmol} / \mathrm{l}$ and $1.3 \pm 0.2 \mathrm{nmol} / \mathrm{l}$ respectively, indicating a 3 - to 4 fold higher potency of SOM230.

\section{In vivo characterization of SOM230}

Effect of SOM230 on GH, insulin and glucagon release in rat Plasma $\mathrm{GH}$ levels are tightly controlled by SRIF and SRIF analogs. We therefore assessed the inhibitory effect of SOM230 (and for comparison SMS 201-995) on GH, insulin and glucagon release in rats by administering increasing doses of SOM230 (SMS 201-995) to assess the respective $\mathrm{ED}_{50}$ value. When measuring 1 hour post drug administration, SOM230 was found to be slightly less active than SMS 201995 in inhibiting $\mathrm{GH}$ secretion $\left(\mathrm{ED}_{50}=0.22 \mu \mathrm{g} / \mathrm{kg}\right.$ s.c). However, SOM230 was much more potent compared with SMS 201-995 when determining the inhibi- tory effect on GH release $6 \mathrm{~h}$ after drug application indicating its prolonged duration of action in vivo (Table 2). At $6 \mathrm{~h}$ post injection, SOM230 still inhibited effectively the $\mathrm{GH}$ release in rats with an $\mathrm{ED}_{50}$ of $5.5 \mu \mathrm{g} / \mathrm{kg}$ s.c., whereas SMS 201-995 was, under these conditions, more than fourfold less active. In this assay BIM 23014 (Somatuline) was the weakest inhibitor of $\mathrm{GH}$ release with an $\mathrm{ED}_{50}$ value of $144 \mu \mathrm{g} / \mathrm{kg}$ s.c. $6 \mathrm{~h}$ post drug application.

Since insulin and glucagon are potential targets for SRIF analog action, we also measured the effect of SOM230 treatment on insulin and glucagon levels $1 \mathrm{~h}$ post injection. Whereas insulin release was inhibited at 15-fold higher doses of SOM230 compared with GH inhibition $\left(\mathrm{ED}_{50}=3.4 \mu \mathrm{g} / \mathrm{kg}\right.$ s.c. $)$, the insulinstimulated glucagon release was even less sensitive to SOM230 inhibition $\left(\mathrm{ED}_{50}=74 \mu \mathrm{g} / \mathrm{kg}\right.$ s.c. $)$. Since SOM230 inhibited insulin secretion in rats, a potential diabetogenic side effect profile was investigated. Plasma samples of a long-term (4 months) study in Lewis rats were analyzed for potential effects of SOM230 on plasma glucose concentrations in response to continuous high dose infusion of SOM230 $(10 \mu \mathrm{g} / \mathrm{kg} / \mathrm{h})$. The glucose levels ranged between 6.7 and $8.0 \mathrm{mmol} / \mathrm{l}$ (placebo) and between 5.8 and $7.4 \mathrm{mmol} / \mathrm{l}$ (SOM230) during the 18-week treatment period, indicating that SOM230 treatment had no significant impact on plasma glucose levels (Fig. 4). At the end of the 126day treatment period glucose concentrations were not significantly different: for control $7.4 \pm 0.5 \mathrm{mmol} / \mathrm{l}$ and

Table 2 Inhibition of GH, insulin and glucagon release in rats by SOM230 and SMS 201-995 determined 1 and $6 \mathrm{~h}$ (for GH) and $1 \mathrm{~h}$ (for insulin and glucagon) after drug application. Results are the $E D_{50}$ values expressed as $\mu \mathrm{g} / \mathrm{kg}$.

\begin{tabular}{lcccr}
\hline Compound & GH 1 hour & GH 6 hours & Insulin 1 hour & Glucagon 1 hour \\
\hline SMS 201-995 & 0.13 & 23.7 & 38.6 & 1.7 \\
SOM230 & 0.22 & 5.5 & 3.4 & 74.0 \\
\hline
\end{tabular}




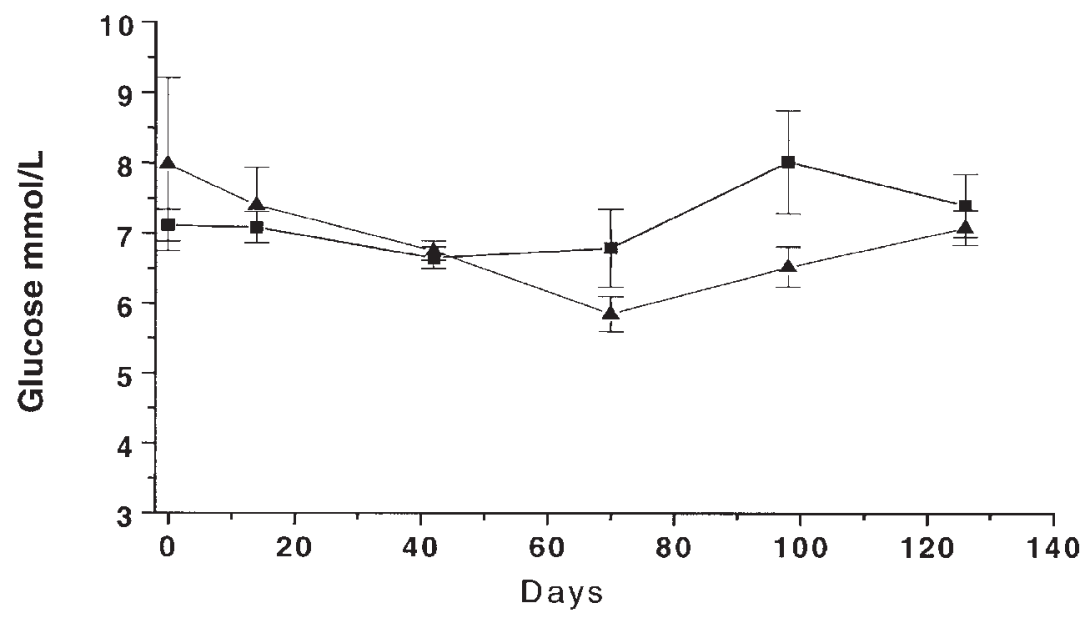

Figure 4 Effect of long-term continuous infusion of SOM230 $(10 \mu \mathrm{g} / \mathrm{kg} / \mathrm{h})$ on plasma glucose levels in rats $(\boldsymbol{\Lambda})$ versus untreated control animals ( $\mathbf{\square})$. Treatment was started on day 0 and values represent means \pm S.E.M. of $n=9-12$ animals. for SOM230-treated animals $7.1 \pm 0.3 \mathrm{mmol} / \mathrm{l}$ (mean \pm S.E.). These results demonstrate that SOM230 is apparently well tolerated and exhibits no diabetogenic effect in rats treated for more than 120 days by continuous high-dose infusion.

Effect of SOM230 on IGF-I release in rats Growth hormone is an important regulator of IGF-I release in peripheral tissues such as liver but IGF-I is also released from liver, kidney and heart in a GH-independent fashion under the control of SRIF (3). Thus SRIF can affect IGF-I levels by both a GH-dependent, and a GHindependent local effect on peripheral target tissues such as liver, heart and kidney. Due to its unique binding profile and pharmacokinetic properties (see below), SOM230 may differ from other short synthetic SRIF analogs in its potency and efficacy to inhibit IGF-I release. To compare the inhibitory profile of SMS 201995 and SOM230 on plasma IGF-I levels in rats, both somatostatin analogs were administered by osmotic minipumps for 126 days. Under these conditions mean plasma IGF-I concentrations in placebo-treated control animals were $1280 \pm 180 \mathrm{ng} / \mathrm{ml}$. Whereas SMS 201-995 treatment resulted in only a partial reduction of plasma IGF-I levels to $940 \pm 50 \mathrm{ng} / \mathrm{ml}$, SOM230 was far more effective and induced a long lasting reduction of IGF-I plasma concentrations to mean values of $320 \pm 110 \mathrm{ng} / \mathrm{ml}$ at day 126 , indicating its high efficacy to inhibit rat plasma IGF-I (Fig. 5).

Pharmacokinetic profile of SOM230 in rats Since SOM230 showed a prolonged duration of action in vivo as shown by its effective inhibition of $\mathrm{GH}$ release $6 \mathrm{~h}$ post drug administration (Table 2), the pharmacokinetic profile of SOM230 in rats after a single subcutaneous bolus injection was assessed. Plasma concentrations were measured for SOM230 and compared with those for SMS 201-995 (Fig. 6). The relatively low systemic clearance indicates that SOM230 does not undergo extensive hepatic metabolism. The distribution-, and the terminal elimination half-life for SOM230 was 0.74 and $23 \mathrm{~h}$ respectively, which are considerably longer than the corresponding values of 0.22 and 2.0 h determined for SMS 201-995 (Fig. 6). The 3- and 11-fold longer distribution, and terminal elimination half-life of SOM230 could provide a direct explanation for the longer duration of action observed in rats when measuring the inhibition of growth

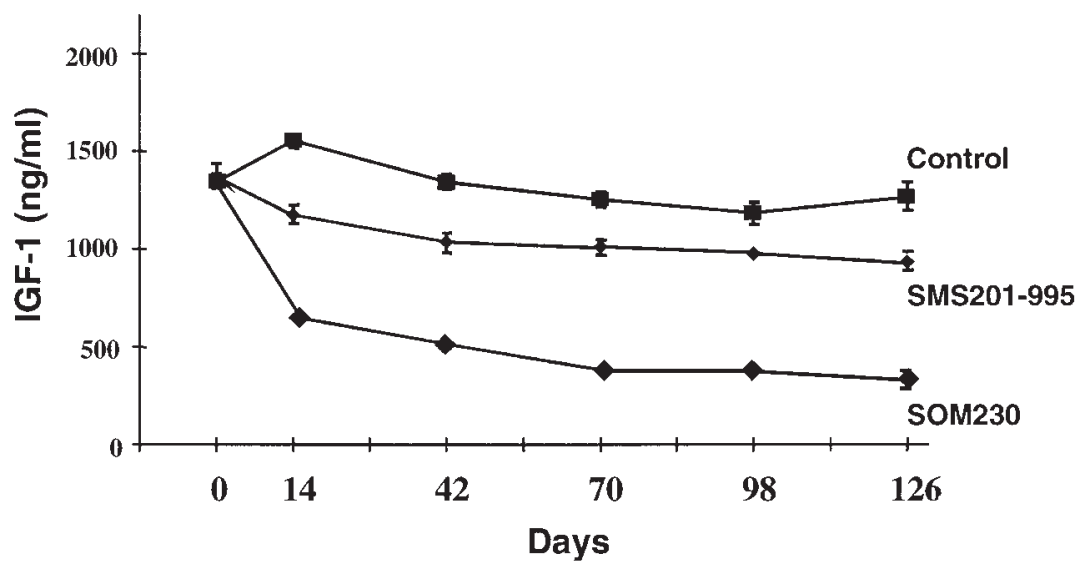

Figure 5 Effect of continuous infusion of SOM230 and SMS 201-995 (10 $\mu \mathrm{g} / \mathrm{kg} / \mathrm{h})$ on plasma IGF-I levels in rats over 126 days (means \pm S.E.M of $n=9-12$ animals). 


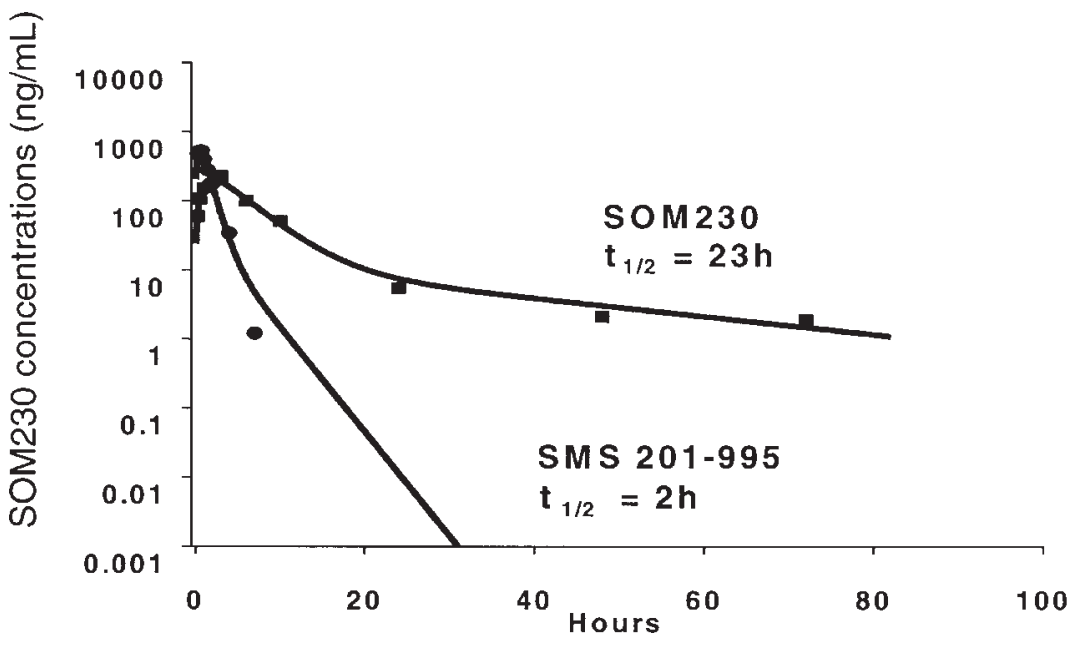

Figure 6 Plasma concentration versus time profiles for SOM230 (ם) and SMS 201-995 $(\bullet)$ in rats following subcutaneous administration of $1 \mathrm{mg} / \mathrm{kg}$ SRIF analog. Symbols represent mean values of $n=4$ animals and lines represent the predictions from the nonlinear regression analysis. hormone release $6 \mathrm{~h}$ post drug application. The prolonged duration of action of SOM230 may allow once daily application instead of three times daily (t.i.d.) injections of currently used SRIF analogs in acute indications.

\section{Discussion}

Somatostatin binds with high affinity to five distinct G-protein-coupled SRIF receptors, sst1-5, while the clinically used short synthetic SRIF analogs, octreotide and lanreotide, bind preferentially with high affinity to the sst2 subtype $(5,12)$. The identification of SRIF receptor subtypes, which differ in their binding properties and pharmacology, has driven the search for novel synthetic SRIF analogs that either bind with high specificity to one certain subtype (25-29) or that bind with high affinity to more than one subtype (21). The few SRIF receptor subtype-selective ligands are on the one hand important tools for characterizing the pharmacological role of each single SRIF receptor subtype and on the other hand some of them may be considered for therapeutic use provided they have appropriate pharmacokinetic properties.

We have focused our approach on identifying SRIF mimetics with a more universal binding profile. In search for a superior SRIF analog with improved therapeutic potential we followed a rational drug design approach aimed at identifying short, metabolically stable cyclohexapeptides that mimic closely the universal binding properties of SRIF-14. Alanine-substituted SRIF-14 analogs allowed the identification of structural elements of SRIF-14 responsible for high affinity binding to hsst1-5 (30). The transposition of these structural elements of SRIF-14 into a cyclohexapeptide template in the form of modified unnatural amino acids such as phenylglycine (Phg) or O-benzyl-tyrosine $(\operatorname{Tyr}(\mathrm{Bzl}))$, resulted in the synthesis of SOM230, a stable peptidomimetic that binds with high affinity to all human SRIF receptor subtypes except sst4. When comparing its binding affinities with those reported previously for octreotide or lanreotide $(10,31)$, major improvements were achieved especially with regard to sst1 and sst5 binding, in that SOM230 binds with a 30-40 times higher affinity to these SRIF receptors subtypes. SOM230 exhibits, in particular, a very high affinity for hsst5, even higher than the affinity measured for the natural ligand SRIF-14 for this receptor subtype.

The binding properties of SOM230 with high affinity binding to the sst 1 , sst 2 , sst 3 , and sst 5 subtypes have to be seen in the light of published observations (for reviews see 12, 18): (i) that single cells, tissues and organs often express more than one somatostatin receptor subtype, (ii) that SRIF receptor subtypes can cross-talk with each other or with other receptor families as has been shown recently for sst 2 , sst 5 and dopamine receptors, $(32,33)$ and (iii) that somatostatin receptor subtype distribution varies across species (34). This rather complex situation of SRIF receptor pharmacology suggests that the therapeutic potential of such a novel, universal SRIF receptor ligand can only be fully explored in the clinical setting.

Among other development candidates SOM230 was selected for in depth in vivo characterization because of its very potent inhibitory effects on GH and IGF-I release and its very high metabolic stability in vivo. In vitro SOM230 is about 3-fold more potent than SMS 201-995 in inhibiting GH release from cultured rat pituitary cells. In rats, SOM230 treatment resulted in a very pronounced reduction of plasma GH and IGF-I levels with a long duration of action and no signs of escape even after continuous high-dose infusion of drug over 18 weeks. The basis for this superiority could be the 40-fold increase in affinity for the sst 5 subtype as compared with SMS 201-995. In fact, studies by Shimon et al. $(35,36)$ indicated that the sst 5 sub- 
type plays a key role in controling GH and prolactin release from human pituitary cells. In line with these findings, it was shown that SRIF analogs with combined affinity for the sst 2 and sst 5 subtypes more effectively inhibit GH release from pituitary adenoma cell cultures and also, importantly, from octreotide-resistant human GH secreting pituitary adenomas (21, 36). Therefore, one area of interest to profile potential therapeutic advantages of SOM230 includes the well established indications for Sandostatin and SandostatinLAR such as treatment of GH-secreting pituitary adenomas and the relief of symptoms associated with gastroenteropancreatic (GEP) tumors induced by excessive hormone secretion (37). The potential therapeutic advantage of SOM230 in these indications is based on its high affinity binding to sst1, sst2, sst3, and sst5 and the observation that pituitary adenomas and GEP tumors often express more than one SRIF receptor subtype. Side-by-side comparisons with octreotide and other short synthetic SRIF analogs revealed that SOM230 had the most attractive inhibitory profile not only on GH, but also on IGF-I release. SOM230 treatment resulted in a very pronounced reduction of plasma IGF-I levels with no signs of escape even after continuous high-dose infusion of the drug over 126 days. Under these experimental conditions SMS 201-995 was only marginally effective on IGF-I inhibition demonstrating a potential therapeutic advantage of SOM230. The strong inhibitory effect on GH and IGF-I secretion also makes SOM230 a candidate drug for the treatment of other diseases such as diabetes-induced complications like micro- and macroangiopathy $(38-41)$ where, according to the $\mathrm{GH}$ hypothesis, the overproduction of $\mathrm{GH}$ is a causal factor in the development of proliferative angiopathy (for review see 42). In addition, Sandostatin has been shown previously to decrease the glomerular filtration rate (GFR) in diabetes-associated renal hyperfiltration (43). Therefore, an SRIF analog that even more effectively suppresses the release of $\mathrm{GH}$ and IGF-I may have a therapeutic advantage over the currently available SRIF analogs in such indication.

Beyond inhibiting GH and IGF-I release, somatostatin and somatostatin analogs have been shown before to reduce the secretion of various other hormones including insulin and glucagon (2, 42). As a consequence hyper-, or hypoglycemia have been reported as potential side effects of SRIF-analog treatment in patients. It was therefore mandatory to investigate the effects of SOM230 on insulin, glucagon and glucose regulation. Treatment with SOM230 in rats resulted acutely, $1 \mathrm{~h}$ after drug application, in the inhibition of insulin release only at 10- to 15-fold higher doses compared with GH inhibition. A weak inhibition of glucagon release was only seen at much higher SOM230 doses. In order to rule out adverse side effects of SOM230 in vivo due to changes in glucose homeostasis, the effect of both SMS 201-995 and SOM230 were characterized in long-term rat experiments. An 18week treatment of rats with SOM230 at a constant infusion rate of $10 \mu \mathrm{g} / \mathrm{kg} / \mathrm{h}$ did not change plasma glucose levels significantly indicating that SOM230 is well tolerated in rats with regard to glucose homeostasis.

Very importantly, the pharmacokinetic properties of SOM230 in vivo differ profoundly from SMS 201-995 in that the terminal elimination half-life of SOM230 is increased more than 10 -fold to $\mathrm{t}_{1 / 2}=23 \mathrm{~h}$ resulting in a long duration of action in vivo as shown by the suppression of $\mathrm{GH}$ release $6 \mathrm{~h}$ after drug application. These improved pharmacokinetic properties of SOM230 could be of great importance since it may offer the possibility of once daily dosing in acute indications where currently used SRIF analogs require t.i.d. dosing, and Stilamine (natural somatostatin, with a half-life $\leq 3 \mathrm{~min}$ ) requires constant infusion therapy.

In summary, SOM230 is a novel SRIF mimetic which is unique with respect to its structure, its receptor binding profile, its potent inhibitory effects on GH and IGF-I release, and its very long plasma half-life. Therefore, SOM230 is a promising development candidate with several potential advantages over currently used SRIF analogs. Early phase I clinical trials have started recently with SOM230 to fully explore the therapeutic potential for this novel SRIF mimetic in man.

\section{References}

1 Brazeau P, Vale W, Burgus R, Ling N, Butcher M, Rivier J et al. Hypothalamic polypeptide that inhibits the secretion of immunoreactive pituitary growth hormone. Science 1973179 77-79.

2 Reichlin S. Somatostatin. New England Journal of Medicine 1983 309 1556-1563.

3 Serri O, Brazeau P, Kachra Z \& Posner B. Octreotide inhibits insulin-like growth factor-I hepatic gene expression in the hypophysectomized rat: evidence for direct and indirect mechanism of action. Endocrinology $19921301816-1821$.

4 Epelbaum J. Somatostatin in the central nervous system: physiology and pathological modifications. Progress in Neurobiology 1986 27 63-100.

5 Bruns C, Raulf F, Hoyer D, Schloos J, Luebbert H \& Weckbecker G. Binding properties of somatostatin receptor subtypes. Metabolism: Clinical and Experimental $1996 \mathbf{4 5} 17-20$.

6 Patel YC. Somatostatin and its receptor family. Frontiers in Neuroendocrinology 199920 157-198.

7 Schoenbrunn A. Somatostatin receptors present knowledge and future directions. Annals of Oncology 199910 17-21.

8 Feniuk W, Jarvie E, Luo J \& Humphrey PPA. Selective somatostatin sst2 receptor blockade with the novel cyclic octapeptide, CYN154806. Neuropharmacology 200039 1443-1450.

9 Reisine T \& Bell GI. Molecular biology of somatostatin receptors. Endocrine Reviews 199516 427-442.

10 Hoyer D, Luebbert H \& Bruns C. Molecular pharmacology of somatostatin receptors. Naunyn-Schmiedeberg's Archives of Pharmacology $19943 \mathbf{3 0} 441-453$.

11 Meyerhof $W$. The elucidation of somatostatin receptor functions: a current view. Reviews of Physiology, Biochemistry and Pharmacology 1998133 55-105.

12 Patel YC. Molecular pharmacology of somatostatin receptor subtypes. Journal of Endocrinological Investigation $199720348-367$.

13 Siehler S, Seuwen K \& Hoyer D. Characterisation of human recombinant somatostatin receptors: 1) radioligand binding 
studies. Naunyn Schmiedeberg's Archives of Pharmacology 1999 $360488-499$.

14 Bauer W, Briner U, Doepfner W, Haller R, Huguenin R, Marbach P et al. SMS 201-995: a very potent and selective octapeptide analog of somatostatin with prolonged action. Life Sciences $1982311133-1140$.

15 Murphy WA, Lance VA, Moreau S, Moreau J \& Coy DH. Inhibition of rat prostate tumor growth by an octapeptide analog of somatostatin. Life Sciences $1987402515-2522$.

16 Karashima T, Cai RZ \& Schally AV. Effects of highly potent octapeptide analogs of somatostatin on growth hormone, insulin and glucagon release. Life Sciences 198741 1011-1019.

17 Newman CB, Melmed S, Snyder PJ, Young WF, Boyajy LD, Levy R et al. Safety and efficacy of longterm octreotide therapy of acromegaly: results of a multicenter trial in 103 patients. A clinical research center study. Journal of Clinical Endocrinology and Metabolism $1995802768-2775$.

18 Lamberts SW, Van Der Lely AJ, De Herder WW \& Hofland LJ. Octreotide. New England Journal of Medicine 1996334 246-254.

19 Afargan M, Janson ET, Gelerman G, Rosenfeld R, Ziv O, Karpov O et al. Novel long-acting somatostatin analog with endocrine selectivity: potent suppression of growth hormone but not of insulin. Endocrinology 2001142 477-486.

20 Parmar RM, Chan WW, Dashkevicz M, Hayes EC, Rohrer SP, Smith RG et al. Nonpeptidyl somatostatin agonists demonstrate that sst 2 and sst 5 inhibit stimulated growth hormone secretion from rat anterior pituitary cells. Biochemical and Biophysical Research Communications 1999263 276-280.

21 Savenu A, Gunz G, Dufour H, Caron P, Fina F, Quafic L et al. BIM23244 , a somatostatin receptor subtype 2- and 5-selective analog with enhanced efficacy in suppressing growth horomone (GH) from octreotide-resistant human GH-secreting adenomas. Journa of Clinical Endocrinology and Metabolism 200186 140-145.

22 Kaupmann K, Bruns C, Raulf F, Weber HP, Mattes H \& Luebbert H. Two amino acids, located in transmembrane domains VI and VII, determine the selectivity of the peptide agonist SMS 201-995 for the SSTR2 somatostatin receptor. EMBO Journal $1995 \mathbf{1 4}$ $727-735$.

23 Fricker G, Bruns C, Munzer J, Briner U, Albert R, Kissel T et al. Intestinal absorption of the octapeptide SMS 201-995 visualized by fluorescence derivatization. Gastroenterology $1991 \mathbf{1 0 0}$ $1544-1552$.

24 ADAPT II.4. User's Guide. Biomedical Simulation Resources, University of Southern California, Los Angeles, 1988.

25 Liapakis G, Hoeger C, Rivier J \& Reisine T. Development of a selective agonist at the somatostatin receptor subtype SSTR1. Journal of Pharmacology and Experimental Therapeutics 1996276 10891094.

26 Rohrer SP, Birzin ET, Mosley RT, Berk SC, Hutchins SM, Shen DM et al. Rapid identification of subtype-selective agonists of the somatostatin receptor through combinatorial chemistry. Science $1998282737-740$.

27 Yang L, Berk SC, Rohrer SP, Mosley RT, Guo L, Underwood DJ et al. Synthesis and biological activities of potent peptidomimetics selective for somatostatin receptor subtype 2. PNAS 199895 10836-10841.

28 Coy DH \& Taylor JE. Development of somatostatin agonists with high affinity and specificity for the human and rat type 5 receptor subtype. Peptide Proceedings of the American Peptide Symposium 199915 559-560.

29 Reubi JC, Schaer JC, Wenger S, Hoeger C, Erchegyi J. Waser B et al. SST3-selective potent peptidic somatostatin receptor antagonists. PNAS 200097 13973-13978.
30 Lewis I, Bauer W, Albert R, Chandramouli N, Pless J, Engel G et al. Peptides: the wave of the future. In 17th American/2nd International Peptide Symposium, pp 718-720. Eds R Houghten \& M Lebl. Dordrecht: Kluwer Academic Publishers, 2001.

31 Bruns C, Weckbecker G, Raulf F, Kaupmann K, Schoeffter P, Hoyer $\mathrm{D}$ et al. Molecular pharmacology of somatostatin-receptor subtypes. Annals of The New York Academy of Sciences 1994733 $138-146$.

32 Rocheville M, Lange DC, Kumar U, Patel SC, Patel RC \& Patel YC. Receptors for dopamine and somatostatin: formation of heterooligomers with enhanced functional activity. Science $2000 \mathbf{2 8 8}$ $154-157$.

33 Rocheville M, Lange DC, Kumar U, Sasi R, Patel RC \& Patel YC. Subtypes of the somatostatin receptor assemble as functional homo- and heterodimers. Journal of Biological Chemistry 2000 $2757862-7869$.

34 Ferone D, van Hagen PM, Colao A, Lombardi G, Lamberts SWJ \& Hofland LJ. Distribution, role and function of somatostatin receptors in immune cells. In Octreotide: The Next Decade, pp 259-275. Ed. SWJ Lamberts. Bristol, UK: BioScientifica, 1999.

35 Shimon I, Taylor JE, Dong JZ, Bitonte RA, Kim S, Morgan B et al. Somatostatin receptor subtype specificity in human fetal pituitary cultures. Differential role of SSTR2 and SSTR 5 for growth hormone, thyroid-stimulating hormone, and prolactin regulation. Journal of Clinical Investigation $199799789-798$.

36 Shimon I, Yan X, Taylor JE, Weiss MH, Culler MD \& Melmed S. Somatostatin receptor (SSTR) subtype-selective analogs differentially suppress in vitro growth hormone and prolactin in human pituitary adenomas: novel potential therapy for functional pituitary tumors. Journal of Clinical Investigation $19971002386-2392$.

37 Lamberts SWJ, Krenning EP \& Reubi JC. The role of somatostatin and its analogs in the diagnosis and treatment of tumors. Endocrine Reviews 199112 450-482.

38 Ørskov H, Flyvbjerg A, Frystyk J, Ledet T, Moller N, Christensen SE et al. Octreotide and diabetes: theoretical and experimental aspects. Metabolism 199241 (9, Suppl 2) 66-71.

39 Hyer SL, Sharp PS, Brooks RA, Burrin JM \& Kohner EM. Continuous subcutaneous octreotide infusion markedly suppresses IGF-I levels whilst only partially suppressing GH secretion in diabetics with retinopathy. Acta Endocrinologica 1989120 187-194.

40 Grant MB, Caballero S \& Millard WJ. Inhibition of IGF-I and b-FGF stimulated growth of human retinal endothelial cells by the somatostatin analog, octreotide, a potential treatment for ocular neovascularization. Regulatory Peptides 199348 267-278.

41 Groenbæk H, Nielsen B, Frystyk J, Ørskov H \& Flyvbjerg A. Effect of octreotide on experimental diabetic renal and glomerular growth: importance of early intervention. Journal of Endocrinology $199514795-102$.

42 Ørskov H, Flyvbjerg A, Groenbæk H \& Moller N. Metabolic and functional effects of somatostatin analogues in diabetes mellitus. In Octreotide: the Next Decade, pp 195-222. Ed. SWJ Lamberts. Bristol, UK: BioScientifica, 1999.

43 Jacobs ML, Derkx FHM, Stijnen T, Lamberts SWJ \& Weber RFA. Effect of long-acting somatostatin analogue (somatulin) on renal hyperfiltration in patients with IDDM. Diabetes Care 1997 $20632-636$

Received 6 February 2002

Accepted 27 February 2002 